\title{
A Conceptual Framework for Manufacturing Service Provisioning by Virtual Fabs*
}

\author{
Yea-Huey $\mathrm{Su}^{1}$, Ruey-Shan $\mathrm{Guo}^{2}$, Shi-Chung Chang ${ }^{3}$ \\ ${ }^{1.2}$ Graduate Institute of Business Administration, National Taiwan University \\ ${ }^{3}$ Graduate Institute of Electrical Engineering, National Taiwan University \\ 蘇雅惠 ${ }^{1}$, 郭瑞祥 ${ }^{2}$, 張時中 ${ }^{3}$ \\ 1,2 台灣大學商學研究所 \\ 3 台灣大學電機工程研究所
}

\begin{abstract}
Fast growth of foundry fabs, fierce global competition and advancements of information technology have motivated in the semiconductor industry the concept of Virtual Fab (VF) with emphasis on manufacturing service provisioning. In this paper, a conceptual framework is proposed for VFs, which consists of three layers: infrastructure, business process, and virtual product layers. Data warehouse, open real-time simulation service, dynamic binding and customer-oriented interface constitute the four key ingredients of the infrastructure. Basic manufacturing business processes in the context of order management are then analyzed and manufacturing services are carefully classified within the VF framework. How the proposed VF infrastructure facilitates these services and how service quality should be managed demand for future research.
\end{abstract}

* This work was supported in part by the National Science Council of the Republic of China under Grants NSC 86-2622-E-002-025R 


\section{Introduction}

In recent years, the risk of running a fab has increased significantly because of the high capital investment and the very dynamic business environment. The industry has responded to the high risk by several business strategies such as strategic alliance and dedicated foundry fab. During the past ten years, particularly in Taiwan, foundry has become one of the fastest growth businesses in the IC industry. It was estimated that $8 \%$ of worldwide production volume is currently provided by foundry fab but this number will increase to more than $20 \%$ in the coming few years. There is no doubt that the foundry business will be even more important in the near future and competition will arise. However, the business model of running a foundry fab is totally different that of a product fab and the value-added activity cannot be analyzed purely based on the traditional "manufacturing" model. A new model which provides customers with "services" in addition to manufacturing capability must be in place.

To serve the needs of fabless semiconductor companies and to respond to new challenges and opportunities for foundry fabs, the concept of "Virtual Fab (VF)" with manufacturing service has been proposed by the industry as one of the critical aspects for achieving competitiveness [9]. Although there have been diversified definitions about the concept and its realization approaches remain ambiguous to most of the practitioners, the VF concept may lead to a service-oriented new business model to IC industry,

Table 1 lists some existing views of VF from different perspectives of both customers and suppliers. For example, tsmc [9], from the foundry fab perspective, defines the VF as the customers' fab. To satisfy many customers, however, the physical fab must provide customerized services and mixed products by dynamically changing operation and capacity configuration. Stanford University [11], from the engineering development perspective, perceives the VF as simulation tools to run in parallel with or before the actual fab for fast process, product, and operation developments. Intel [1], from the fab ramp up perspective, views the VF as an integrated test/development hub and "copy it exactly" to many fabs. Siemens [20], on the other hand, views VF as a capability to copy intelligently to many fabs. Different processing machines are allowed in different fabs as long as key product parameters are matched. This is also similar to National's [21] definition, which requires quality portability among either internal or external fabs. 
Table 1: Various views of virtual fab

\begin{tabular}{|c|c|c|}
\hline Source & Concept & Characteristics \\
\hline tsmc & - Customer's fab & $\begin{array}{l}\text { - Foundry fab } \\
\text { - Customized services } \\
\text { - Mixed products } \\
\text { - Dynamic operational and capacity configuration }\end{array}$ \\
\hline Stanford U. & - Simulated fab & $\begin{array}{l}\text { - Virtual fab and real fab in parallel for fast } \\
\text { process, product, and operation developments }\end{array}$ \\
\hline Intel & - Copy Exactly & $\begin{array}{l}\text { - Integrated test/development hub } \\
\text { - Fast fab ramp up }\end{array}$ \\
\hline Siemens & - Copy Intelligently & $\begin{array}{l}\text { - A reference site } \\
\text { - Centralized technology development } \\
\text { - Process match (key product parameters) } \\
\text { - Exploitation of local strength by allowing } \\
\text { different processing machines } \\
\text { - Centralized process change review }\end{array}$ \\
\hline $\mathrm{NSC}$ & - Square Beaker & - Making mixed signal products portable \\
\hline
\end{tabular}

Our goals in this paper are to

1) define and propose a conceptual framework of VF, and

2) define and classify manufacturing services in the context of order management.

Under such goals, the remainder of the paper is organized as follows. Section 2 describes the proposed VF framework and architecture. Order management-related business processes and manufacturing services are then classified in Section 3. Finally, Section 4 gives some concluding remarks.

\section{Virtual Fab Definition}

There have been many definitions in the literature about virtual enterprise in general and virtual manufacturing in specific. We define a virtual fab by combining the salient features of $\mathrm{IC}$ wafer fabrication business and the generic concepts of virtual manufacturing.

\subsection{Nature of Virtuality}

In order to construct a conceptual framework of VF, the nature of virtuality is first explored and defined. Based on our study, the elements of virtuality can be summarized as: separation, transparency, real-time simulation, and customization [5].

First, the concept of separation is that one is able to separate himself from time and/or space within a virtual environment. That is, one may get involved with an activity without being physically on-site or without being synchronous. Separation 
can be applied to tangible and intangible entities and is usually intended to increase the performance or efficiency. For example, separating the container from a truck reduces the waiting time to load/unload cargo. The application of EDI (electronic data interchange) is based on the idea of separating information flow from goods flow. Okumoto (electronic chicken), a popular new toy, is another good example of separation. Instead of breeding a "real" chicken, one may take care of a "virtual chicken" whose behavior simulates the real chicken. Okumoto separates the behavior from the chicken's body.

Second, transparency refers to the ability to access information without physically owning the information. To be more specific, the information provider must design a system so that users of different locations, different platforms, different application tools, and different organizations can access the data without difficulty.

Third, simulation is the activity of imitating the real-world facilities or processes. The facility or process of interest is usually called a system. In the IC fabrication scenario, it can be a device, a process, or the factory itself. For example, consider a manufacturing firm that is contemplating building a large extension onto one of its plants but is not sure if the potential gain in productivity would justify the construction cost. It certainly would not be cost-effective to build an extension and then remove it later if it does not work out. However, a careful simulation study could shed some light on the question by simulating the operation of the plant as it currently exists and as it would be if the plant were expanded. In general, simulation itself is already a useful tool in practice; however, it is "real time" performance that makes virtuality possible. By real time, we mean that the simulated results must be fast enough to promote the interactions between the users and the simulated system.

Finally, Customization refers to the flexibility to fit different users' needs in a dynamic environment. This has two implications. To the users, the feeling of virtuality comes from the customized interface specifically designed to satisfy them. To the system designers, the system itself must have the flexibility to adjust its internal operations dynamically to respond to the external needs.

\subsection{Conceptual Framework}

Based on the nature of virtuality, a conceptual framework for VF is proposed. As shown in Figure 1, there are three layers in this framework. The bottom layer is the infrastructure layer which includes four key ingredients: data warehouse, open real-time simulation, dynamic binding service [10], and customer-oriented interface. The middle layer is the traditional business process layer which includes the 
customer-contact processes and non-customer-contact processes [12]. The top layer is the delivered virtual product layer which is divided into three types: serviced time, information, and possession [19]. Each of the layers will be explained below.

\begin{tabular}{c|c|c|c|}
\cline { 2 - 3 } Virtual Product Layer & Serviced time & Information & Possession \\
\cline { 2 - 4 } Business Process Layer & $\begin{array}{c}\text { Customer-contact } \\
\text { processes }\end{array}$ & $\begin{array}{c}\text { Non-customer-contact } \\
\text { processes }\end{array}$ \\
\cline { 2 - 4 } Infrastructure Layer & \multicolumn{2}{|c|}{$\begin{array}{c}\text { Virtual Fab Architecture: } \\
\text { Data warehouse, open real-time simulation, dynamic } \\
\text { binding service, customer-oriented interface }\end{array}$} \\
\hline
\end{tabular}

Figure 1: Virtual fab conceptual framework

\subsection{Architecture}

In our definition, a virtual fab is an environment that provides transparent descriptions and simulations of a semiconductor wafer fab to internal/external users, who are separated from the real entity in space and/or time, via open and easy access and real time response to user specific needs. Based on this definition, an architecture is proposed in Figure 2. Four key ingredients are identified: data warehouse, open real-time simulation, dynamic binding service, and customeroriented interface.

The data warehouse is a centralized data base (physical or logical) that integrates all the data generated in every business process inside or outside a fab. It must be set up in the early phase of a VF construction. The fact that customers often request data stored in various locations and formats make the demand for data integration imperative. A data warehouse provides an easy access of up-to-date fab data. It maintains consistent, and integrated data/information to various users. Via properly differentiated reporting interface, it provides information on demand service with customized data portfolio. A good data warehouse has the features of easy access, transparency, integrity, timeliness, and security [3, 4]. A data warehouse may largely reduce the time and cost in reporting both internally and externally. It prevents errors and improves data quality through integrated data management. As a result, its timely provisioning of accurate data and sufficient information may shorten decision-making life cycle, help raise decision quality, and allow users to cope with changes via clear situation assessments. 


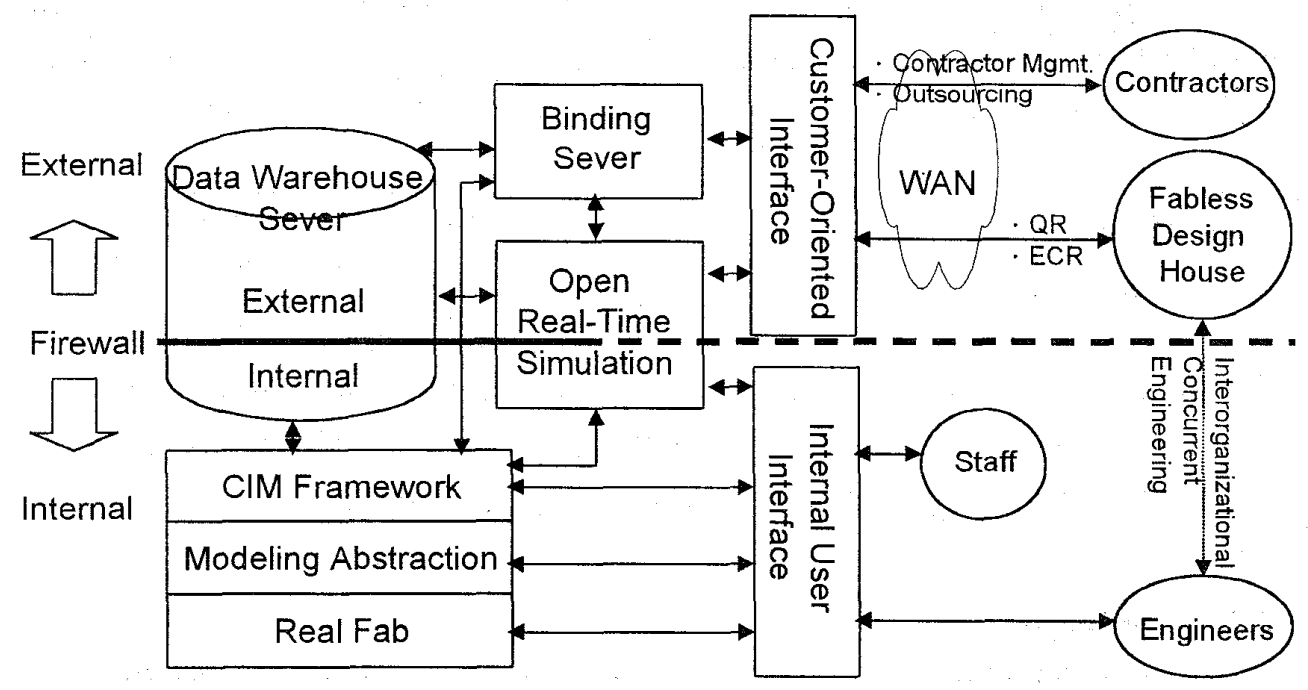

Figure 2: Virtual fab architecture

An open real-time simulation service (ORTS) provides a real-time simulation environment where simulation resources are open to customer access. In addition to the data model behind a data warehouse, modeling effort must be carried out from the highest fab level to the most detailed device level and from views of function, information, resource and organization. A complete fab reference model provides a common language for communication and integration; it may also depict a clear picture of both the fab system and its associated business processes. Product, process and production flow models can be used to support simulation tools for optimizing product and production plans, process parameters, quality control policies and other fab operation conditions. ORTS tools are critical to support competitive manufacturing services and constitute a part that is not easily copied by competitors. To provide ORTS, effective models for various levels and purposes must be constructed, and it takes time and experience to develop good models. The complete ORTS is able to provide simulation services on product, process and production flow independent of platform and software. As ORTS can be used for what-if analysis, prediction/extrapolation and virtual prototyping, it will serve as a significant decision support tool to both internal users and customers $[2,17]$.

To make the manufacturing service available to customers' requests and to allow effective access to all the fab resources that constitute a service, including data, software, hardware, human resources, and business processes, the fab must possess the ability to break down the requested service and effectively integrate all the available resources. Dynamic binding service [10] facilitates such service break down and resource marshaling processes. It integrates functions such as resource 
registration, activation, scheduling and optimization. Resource registration is to take all resource available into binding service's control umbrella. Resource management is to automate the resource scheduling, optimization and allocation processes. While customer-end interface must make easy the task of customers to issue requests, the fab must at the same time take care of all the complexity behind each request via dynamic binding mechanism.

A customer-oriented interface is the carrier through which customers feel the existence of VF. Most of the services provided by VF, including order status check, what-if planning, production flow simulation, and process simulation must be executed through the customer-oriented interface. Therefore, the design and quality of this interface is key to the success of VF. There are three important features in this customer-oriented interface: customization (contents) [8], transparency (presentation), and flexibility [18].

\section{Manufacturing Services}

Directly on top of the VF infrastructure layer are the business process and virtual product/service layers. Since our goal is to provide services in addition to manufacturing capability, we need to carefully classify manufacturing services within the VF scenario and determinant how the proposed infrastructure may facilitate these services

\subsection{Business Processes}

Business processes are divided into customer-contact and non-customer-contact processes. Service delivery processes require direct customer contact and are visible to customers. In contrast, service operation processes do not involve direct service contact and are traditionally invisible to customers. Figure 3 depicts the traditional functional flow or value chain model [16]. Value is created during different stages and customers may not get involved with the creation process. In fact, in the traditional business process flow, customers receive services mostly in the sales/marketing and after-sale service stages.

In the foundry business, as product complexity and add-on value increase while product/technology life cycle decreases, tightly coupled, concurrent interactions between customers and manufacturers in the value adding process become indispensable to their respective competitiveness such as high yield and quick response time. Through a VF infrastructure, customers can now be interfaced with 
any production stage through one unified channel. This capability, in turn, creates "virtual products" in addition to tangible products. In other words, customers virtually can access virtual products via multiple service encounters ${ }^{* *}$, but physically access face-to-faced services via only one service encounter as in the traditional business process.

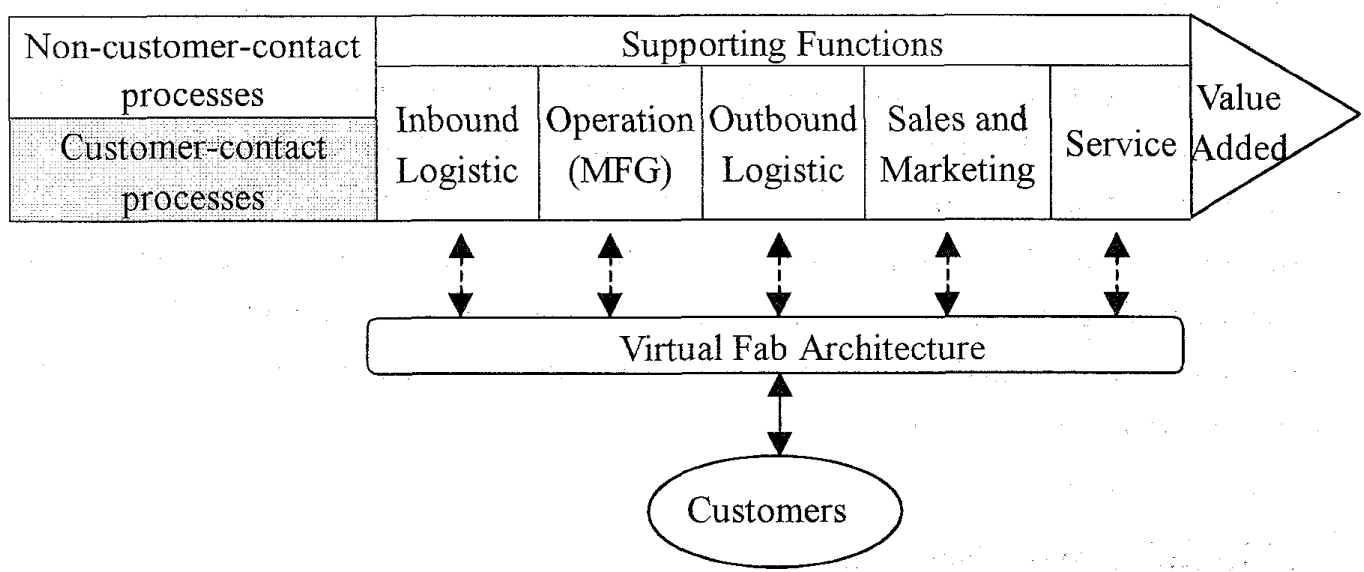

Figure 3: Single service encounter vs. multiple service encounters

To better understand what values or services that might be created during the production process, the skeleton of a business process flow is analyzed. For example, in a typical ordering process, we decompose the process into several stages as shown in Figure 4 [6]. Some core activities are also listed for each stage. In the one hand, a VF facilitates these business activities and results in both real and virtual products. On the other hand, business process reengineering may be motivated by the introduction of VF concepts.

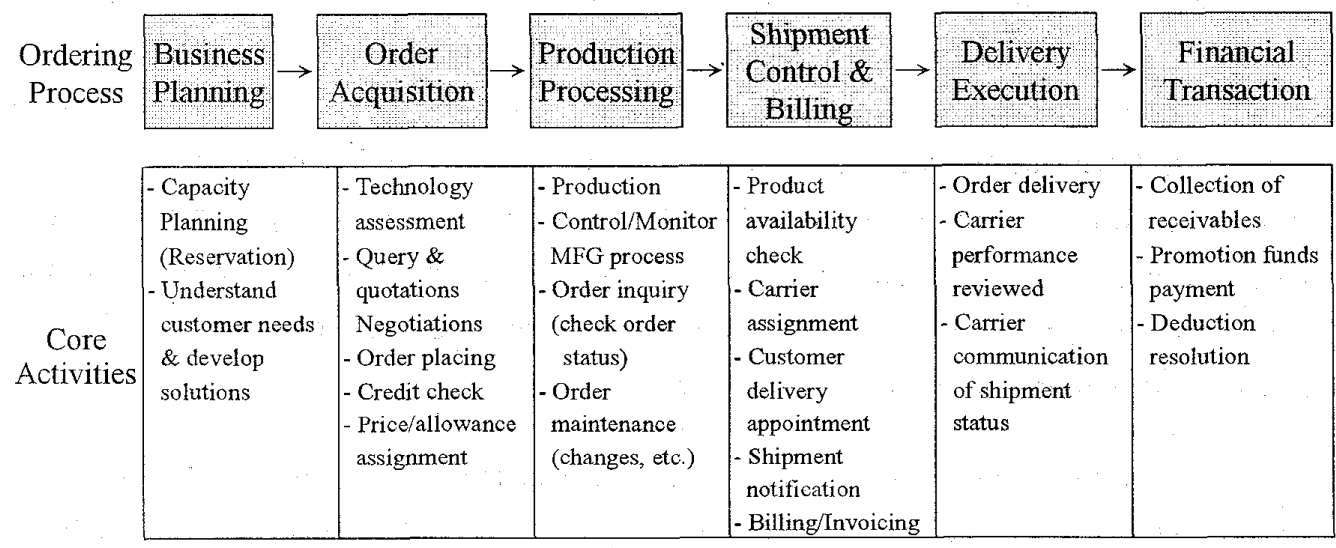

Figure 4: Ordering process activities

\footnotetext{
** Service encounter defined as "a period of time during which a customer interacts directly with a service". The nature and extent of service encounters vary widely according the level of customer contact with the organization and its personnel [12].
} 


\subsection{Virtual products and manufacturing services}

In our framework, the virtual product layer adds a new dimension of virtual products to business activities involving information goods and services. Briefly speaking, virtual products refer to the intangible products produced during the production process. Their content usually determines the service level and in many cases, determines the perceived value from the customers' point of views. In our framework, we have tried to define three types of virtual products: serviced time, information, and possession [19]. Table 2 lists their respective definitions and examples in a typical business process of manufacturing.

Table 2: Virtual product types in a manufacturing business process

\begin{tabular}{|c|c|c|}
\hline $\begin{array}{l}\text { Virtual } \\
\text { Product }\end{array}$ & Definition & Examples \\
\hline $\begin{array}{l}\text { Serviced } \\
\text { time }\end{array}$ & $\begin{array}{l}\text { - Periods available for specific purposes } \\
\text { - Customers consume the time of } \\
\text { professional staffs }\end{array}$ & $\begin{array}{l}\text { - Similar to the service from consultants, } \\
\text { doctors, or lawyer } \\
\text { - Technology assessment by consulting } \\
\text { professional engineers } \\
\text { - Negotiation with professional sales } \\
\text { representatives }\end{array}$ \\
\hline Information & $\begin{array}{l}\text { Knowledge of technology, event, or } \\
\text { status } \\
\text { Customers acquire their concerned } \\
\text { knowledge }\end{array}$ & $\begin{array}{l}\text { Similar to the contents of electronic } \\
\text { magazines or FedEx's web-based } \\
\text { package tracking service } \\
\text { - Query related information for concern } \\
\text { - Check order status or delivery status }\end{array}$ \\
\hline Possession & $\begin{array}{l}\text { Token or reservation right from fab } \\
\text { during a specific period } \\
\text { - Customers keep the token or right for } \\
\text { exchange related service(s) in specific } \\
\text { conditions }\end{array}$ & $\begin{array}{l}\text { - Similar to airlines' seat reservation } \\
\text { service } \\
\text { - Receive capacity reservation from fab }\end{array}$ \\
\hline
\end{tabular}

With the introduction of the business process and virtual product concept, we now define a manufacturing service as the integration of service provisioning into a manufacturing process. It includes not only the end-to-end process but also the associated services. This philosophy is consistent with the current thinking of business re-engineering (organizing around a process instead of a function) and total quality management (providing service quality in addition to physical products). Figure 5 shows a classification of manufacturing services based on a typical manufacturing business process flow and virtual product types just defined. For example, for the purpose of business planning service provisioning, a VF should provide customer-need realization service and capacity reservation service. These services facilitate fabless customers and contractors to effectively plan their own business plans. 


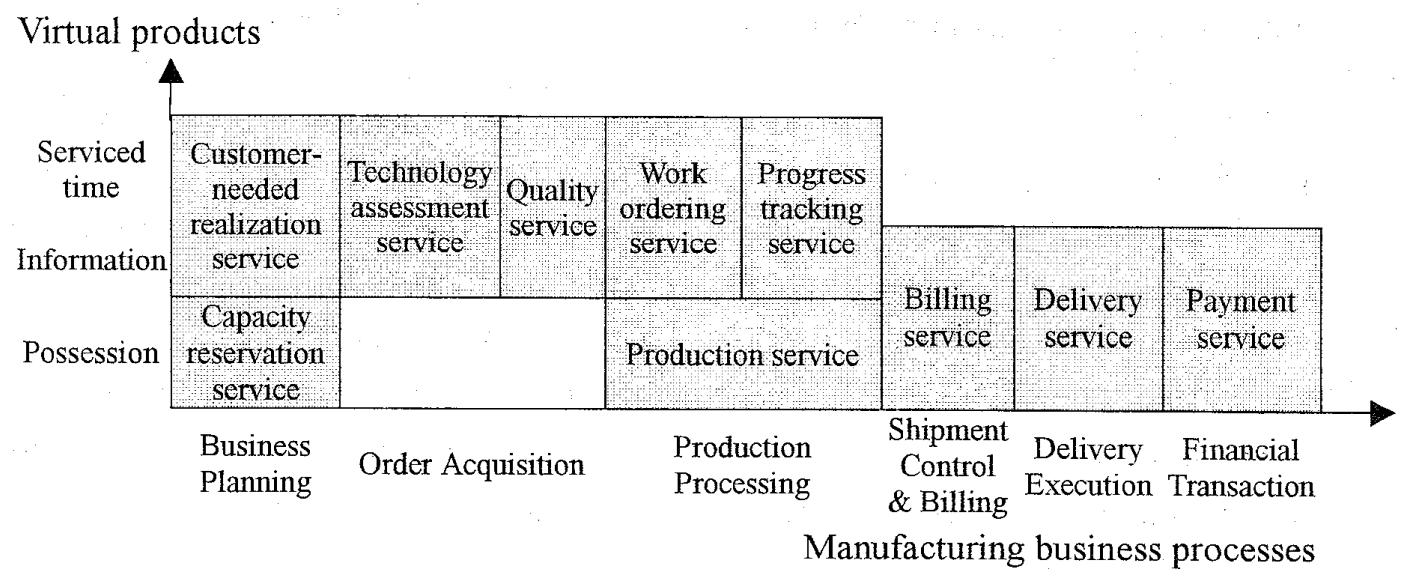

Figure 5: Manufacturing service classes

\section{Concluding Remarks}

A conceptual framework for VF has been defined in this paper. Manufacturing services and virtual products of VF have also been preliminarily identified. However, our proposed VF framework does not address how quality measures of manufacturing services (QoS), such as cycle time, cost, flexibility, and yield [7, 13, 14, $15]$, should be effectively managed. In addition to in-depth study of manufacturing service and virtual product provisioning under our proposed VF, our on-going research includes definition of significant QoS metrics for foundry fabs, translation of global QoS specifications to local performance requirements for fab entities, and QoS management in the VF framework. Results will be reported in future papers.

\section{References}

[1] J. Bisgrove, "Integration Test Facility - Automation Testing to Support Intel Manufacturing Output," Proceedings of Sixth International Symposium on Semiconductor Manufacturing, 1997.

[2] D. E. Carter, B. S. Baker, Concurrent Engineering, Addison-Wesley, 1992.

[3] D. N. Chorafas, Manufacturing Database and Computer integrated systems, CRC press, Boca Raton, Florida, 1993.

[4] S. T. Gelman and W. D. Peck, "Bringing business information to AT\&T network systems through a data warehouse," AT\&T technical journal, pp.68-78, March/April 1996.

[5] R. S. Guo, Y. H. Su, S. C. Chang, Y. W. Lee, and T. L. Chou, "Real Competitiveness via Virtual FAB," Proceedings of the 1997 National Conference on Management of Technology (I) ' pp. 156-163, 1997.

[6] Harvard Business School, "Procter \& Gamble: Improving Consumer Value 
Through Process Redesign," HBR Case 9-195-126, March 31, 1995.

[7] R. H. Hayes, S. C. Wheelwright, and K. B. Clark, Dynamic ManufacturingCreating the Learning Organization, The Free Press, NY, 1988.

[8] J. Hopland, "IT strategy for profitably providing high level customer service," Information Strategy, pp.17-28, winter 1997.

[9] E. Korczynski, "ERSO's Children Grow Up," Solid State Technology, pp. s14s15, s23-s24, February 1997.

[10] A. A. Lazar, K.S. Lim, and F. Marconcini, "Realizing a Foundation for Programmability of ATM Networks withnthe Binding Architecture," IEEE Journal on Selected Areas in Communications, vol.14, no.7, September 1996.

[11] P. Losleben, The Stanford Semiconductor Manufacturing Research Program, Status Report on a Major Research Thrust in the Center for Integrated Systems, Stanford University, Feb. 1992.

[12] C. H. Lovelock, Services Marketing, $3^{\text {rd }}$ ed., Prentice Hall, 1996.

[13] J. Mcgehee, J. Hebley, and J. Mahaffey, "The MMST computer-integrated Manufacturing system framework," IEEE transaction on semiconductor manufacturing, Vol.7, No.2, pp.107-115, May 1994.

[14] H. Nordahl and C. Nilsson, "Making manufacturing flexibility operational," Integrated manufacturing systems, vol.6, no. 1, pp.5-11, 1996.

[15] A. Obank, P. Leaney, and S. Roberts, "Data management within a manufacturing organization," Integrated manufacturing systems, vol.6, no.3, pp.37-43, 1995.

[16] M.E. Porter, Competitive Advantage, New York: Free Press, 1985.

[17] M. Thompson, "Simulation based scheduling," IIE Solutions, pp.30-34, May 1996.

[18] J. K. Whetzel, "Integrating the world wide web and database technology," $A T \& T$ technical journal, pp.38-46, March/April 1996.

[19] M. Yesil, Creating Virtual Store: Taking Your Web Site from Browsing to Buying, New York: John Wiley \& Sons, 1997.

[20] Keynote speech of IEEE International Symposium on Semiconductor Manufacturing Conference, 1997 (ISSM97).

[21] Personal communication to National's foundry service director. 